Journal of Research in Interprofessional

Practice and

Education

Vol. 1.2

August, 2010

\title{
Influencing Student Beliefs about Poverty and Health through Interprofessional Community-Based Educational Experiences
}

\author{
Peggy Proctor, BSc(PT); Deborah Lake, MA, PhD; \\ Lisa Jewell, MA; Louise Racine, RN, PhD; \\ Marcel D'Eon, MEd, PhD; Bruce Reeder, MD, MHSc
}

\begin{abstract}
Background: Pre-licensure students from medicine, physical therapy, kinesiology, nursing, and social work participated in a population health project at the University of Saskatchewan. We assessed the effect of this interactive, interprofessional, community-based educational experience on students' attitudes and beliefs about poverty and health.

Methods and Findings: Participants $(N=119)$ completed two measures at the beginning and end of the five-week project: the 37-item Attitudes toward Poverty Scale (APS) and the 8-item Beliefs about the Relationship between Poverty and Health (BRPH). APS scores showed a modest significant increase toward more positive attitudes over time $(F(1,110)=7.97, p<.01)$. On the BRPH, participants agreed significantly less at Week 5 with two behavioral explanations $(F(1,114)=5.07, p<.05$; $F(1,114)=11.00, p<.01)$ and one structural explanation $(F(1,112)=11.09, p<.01)$ about relationships between poverty and health. There was some evidence that face-to-face interactions with community members had more impact than a simulation exercise. Students gave positive evaluations of the interprofessional format of the project. Attrition effects may limit the interpretation of these results.

Conclusions: Results demonstrate that brief interprofessional community-based learning experiences can positively influence students' attitudes and beliefs about the relationship between poverty and health.
\end{abstract}

Keywords: Interprofessional education; Population health; Poverty

\section{Introduction}

Evidence affirms poverty as the most powerful social determinant of health $[1,2]$. Local research has provided compelling data on the magnitude of health disparity by neighbourhood income [3]. This report indicated that core neighbourhoods (inner-city neighbourhoods with many residents of lower socioeconomic status according to census data) had dramatically higher rates of disease and infant mortality as well as decreased life expectancy compared to middle- or higher-income neighbourhoods. Lemstra and colleagues [4] articulated the need to sensitize health sciences students to these issues without reinforcing a blaming-the-victim mentality toward people living in poverty.

We feel strongly that future health professionals must be educated about these issues and that fostering an "inequalities imagination" [5] in students will help promote anti-discriminatory and anti-oppressive attitudes among healthcare providers. The inequalities imagination framework helps students and practitioners think about their work with underserved populations and the contexts in which they pro- 
146

Student Beliefs about Poverty and Health

Proctor, Lake, Jewell, Racine, D'Eon, \& Reeder

Journal of Research in Interprofessional Practice and Education

Vol. 1.2

August, 2010 vide healthcare [5]. Derived from Campinha-Bacote's [6] work on cultural competency, this framework assumes that awareness of structural inequities is a conscious process similar to the one involving the development of cultural awareness. As a starting point, encountering structural inequities is a prerequisite to developing awareness, the same way that cultural awareness cannot be developed without encountering culturally different others. Successful immersion in underserved neighbourhoods has been reported to contribute to educating socially conscious healthcare professionals in the United States [7].

The Interdisciplinary Population Health Project (IPHP) endeavours to foster an inequalities imagination in undergraduate health sciences students through interactive, interprofessional, local community-based learning experiences. It began in 1999 when two instructors (PP \& BR) at the University of Saskatchewan arranged for small groups of physical therapy and medical students to visit community agencies and report on the role and function of these agencies. Although this was an important start, we soon realized that we must partner with the wider community in a significant way to design more relevant and interactive experiences. Fortunately, two larger initiatives connected with our university community provided opportunities to develop this project.

The first initiative was an interdisciplinary community-university student partnership (known as IICUSP) that was formed in 2001 to bring together university health sciences programs and a number of community-based organizations active in Saskatoon's core neighbourhoods. The community-based organizations included a child hunger education program, a community economic development agency, an AIDS service organization, and a health clinic. One goal of IICUSP was to create learning experiences in community-based interdisciplinary settings, through joint programming and collaborative curricular design.

The second initiative was the provincial Patient-Centered Interprofessional Team Experiences (P-CITE) project, launched in June 2005 and funded by Health Canada. One of its goals was to effect systemic, structural change in health professional education with an emphasis on collaborative practice, patient-centered care, and interprofessional education. P-CITE funding provided our team with resources to coordinate and evaluate the IPHP.

By 2007, a coalition of like-minded faculty from five health provider training programs managed the IPHP. This group shared a commitment to social accountability in health professional preparation and interprofessional education. By partnering with community-based organizations, we hoped this material could come alive for students through the IPHP.

\section{Project overview}

In 2007, the IPHP was a 10-hour collaborative group project held over five weeks in September and October. A total of 193 students participated: 15 from Kinesiology (KIN), 61 from Medicine (MED), 55 from Nursing (NUR), 31 from Physical Therapy (PT), and 31 from Social Work (SW). All students were in the third or fourth year of their respective programs, and were expected to participate in the 
147

Student Beliefs about Poverty and Health

Proctor, Lake, Jewell, Racine, D'Eon, \& Reeder

Journal of Research in Interprofessional Practice and Education

Vol. 1.2

August, 2010 project as a mandatory component of course work. Each student was assigned to one of 20 teams of 9 or 10 students, and teams were balanced for gender and program. There was no designated comparison group of comparable students who did not participate, since the IPHP was considered mandatory for each cohort of students from the various programs.

The IPHP had the following learning objectives: 1) develop attitudes and skills necessary for successful interdisciplinary teamwork; 2) apply logical, critical thinking in recognizing and addressing population health issues using real data and a community development model; 3) explore the role of existing community resources in working with a community toward improving health outcomes; and 4) locate the determinants of health in a larger social, political, and economic perspective. Community development is a central concept of this IPHP because it encompasses a broader view of health and its determinants rather than solely focusing on health indicators and lifestyles [8]. From a community development perspective, students locate health determinants in a socio-ecologic perspective that accounts for the variability in health outcomes among marginalized populations [9]. In this article, we report on measures assessing changes in students' attitudes and beliefs about poverty and health (objectives 2 and 4 ), and students' evaluations of the project components (objective 3). Additional research data related to objective 1 will be reported elsewhere.

To achieve these objectives, diverse cooperative and experiential learning activities were offered, following a blueprint for interprofessional learning [8], as shown in Table 1. All students participated in large group assessment sessions and small group (team) meetings in Weeks 1 and 5. Students chose either the Community Plunge or the SWITCH Program. This choice was offered because students who volunteered for SWITCH had an orientation that was essentially equivalent to the Community Plunge. Finally, students were randomly assigned, within the constraints of constructing groups balanced for gender and program, to either the Poverty Awareness Workshop or the Guest Interview. The Poverty Awareness Workshop was new to the IPHP this year and we wanted to evaluate its effect. All students completed online modules on teamwork called "Pathways to Collaboration" and two assignments: a team assignment on public policy and an individual online journaling assignment on interprofessional collaboration.

\section{Project components}

The Community Plunge provided IPHP participants with a three-hour interactive orientation to Saskatoon's core neighbourhoods with a focus on a) health determinants and development issues; b) community-based approaches and resources; and c) linking local to global issues. Each plunge included a guided community walkabout facilitated by IICUSP. The facilitators of the Community Plunge were leaders of community-based organizations and are regarded as experts in the field.

The Student Wellness Initiative toward Community Health (SWITCH) is a yearround after-hours student-managed health clinic that has served residents of Saskatoon's core neighbourhoods since October 2005. SWITCH offers interprofes- 
148

Student Beliefs about Poverty and Health

Proctor, Lake, Jewell, Racine, D'Eon, \& Reeder
Journal of Research in Interprofessional Practice and Education

Vol. 1.2

August, 2010
Table 1

\section{Components of the Interdisciplinary Population Health Project (IPHP)}

\begin{tabular}{|c|c|c|c|c|c|}
\hline Week 1 & \multicolumn{2}{|c|}{$\begin{array}{l}\text { Large group orientation and assessmen } \\
\text { ( } 30 \text { minutes) followed by }\end{array}$} & \multicolumn{2}{|c|}{$\begin{array}{l}\text { Small group team building } \\
\text { and planning } \\
\text { (1 hour } 20 \text { minutes) }\end{array}$} & \multirow{3}{*}{$\begin{array}{l}\text { Online modules } \\
\text { on teamwork } \\
\text { completed } \\
\text { independently } \\
\text { throughout the } \\
\text { project ( } 3 \text { hours) }\end{array}$} \\
\hline $\begin{array}{l}\text { Weeks 2, 3, 4: } \\
\text { Each small group } \\
\text { does one option } \\
\text { each week }\end{array}$ & $\begin{array}{l}\text { Community Plunge } \\
\text { ( } 3 \text { hours) } \\
\text { or } \\
\text { SWITCH orientation and } \\
\text { shift (4 hours) }\end{array}$ & \multicolumn{2}{|c|}{$\begin{array}{l}\text { Guest Interview } \\
\text { ( } 2 \text { hours) } \\
\text { or } \\
\text { Poverty Awareness } \\
\text { Workshop ( } 4 \text { hours) }\end{array}$} & Week off & \\
\hline Week 5 & \multicolumn{2}{|c|}{$\begin{array}{l}\text { Small group discussion on teamwork } \\
\text { (1 hour) followed by }\end{array}$} & \multicolumn{2}{|c|}{$\begin{array}{l}\text { Large group assessment } \\
\text { and feedback (50 minutes) }\end{array}$} & \\
\hline
\end{tabular}

sional, collaborative, and holistic healthcare by people sensitive to local community and cultural dynamics. Student participation in SWITCH is completely voluntary. Students from post-secondary programs in social work, psychology, medicine, nursing, physical therapy, kinesiology, public health, educational psychology, nutrition, dentistry, pharmacy, and arts and sciences work alongside a professional staff consisting of a physician, nurse, cultural support worker, and one or more licensed mentors from a variety of disciplines. Students who volunteered for SWITCH for the IPHP participated in a minimum of a four-hour orientation session and one fourhour work shift.

Guest Interviews were organized in collaboration with community-based organizations who recruited volunteers from core neighbourhoods to be interviewed by the IPHP student teams. Each guest was invited to tell their own story during the interview session to share their lived experience and perspectives with the healthcare workers of the future. The students structured their onehour interview using a practical, patient-based approach to obtaining a social history [9]. Following the interview, students spent another hour together to identify determinants of health that were relevant to the lived experience of their particular guest.

The Poverty Awareness Workshop was led by low-income facilitators at a venue in a core neighbourhood. This workshop was originally developed as the Poverty Game by a group of Canadian women living on social assistance, and adapted by the Saskatoon Anti-Poverty Coalition in partnership with the Saskatoon Health Region. Using a board-game format, students took on the role of a low-income person juggling a limited income each month. The four-hour workshop ended with a simulated meeting with the Minister of Social Services to advocate for changes to public policy. Before leaving, participants were asked to think about how their experience and learning from the workshop will affect their future work. 


\section{JRIPE}

149

Student Beliefs about Poverty and Health

Proctor, Lake, Jewell, Racine, D'Eon, \& Reeder

\section{Method}

The purpose of this study was to assess the effect of the IPHP on students' attitudes and beliefs about poverty and health. Specifically, we hoped to find that:

- IPHP participants would have more positive attitudes toward people living in poverty at the end of the project;

- IPHP participants would develop a deeper understanding of the structural relationship between poverty and health.

We also wanted to find out whether the Poverty Awareness Workshop, new to our project this year, was comparable to the Guest Interview as an educational experience. Finally, we wanted to compare the attitudes and beliefs of those students who volunteered for SWITCH with non-volunteers, since previous research has indicated that students who volunteer for community service may differ in significant ways from non-volunteers $[10,11]$.

\section{Participants}

Ethics approval for this research was obtained from the University of Saskatchewan Behavioural Research Ethics Board. Of the 193 students enrolled in the IPHP, 162 (84\%) gave informed consent to participate in our research. Table 2 shows the distribution of participants across programs and project components. Most participants were female, and most of the male participants were MED students. Because of the limited number of trained facilitators for the Poverty Awareness Workshop, fewer participants $(30 \%)$ were assigned to this option than to the Guest Interview (70\%). SW students were not able to participate in the Poverty Awareness Workshop because of time constraints within their program. All participants were offered an option of volunteering in SWITCH instead of taking the Community Plunge: 39 (24\%) took this option, of whom 33 (85\%) were female. No KIN students volunteered to participate in SWITCH.

Table 2

\section{Distribution of IPHP participants across programs and project components}

Journal of Research in Interprofessional Practice and Education

Vol. 1.2

August, 2010

\begin{tabular}{|c|c|c|c|c|c|}
\hline Program & $\begin{array}{c}N \\
\text { (\% Female) }\end{array}$ & $\begin{array}{l}\text { Community } \\
\text { Plunge } \\
(n)\end{array}$ & $\begin{array}{c}\text { SWITCH } \\
\text { Volunteers } \\
(n)\end{array}$ & $\begin{array}{l}\text { Guest } \\
\text { Interview } \\
(n)\end{array}$ & $\begin{array}{l}\text { Poverty Awareness } \\
\text { Workshop } \\
(n)\end{array}$ \\
\hline Kinesiology (KIN) & $\begin{array}{c}12 \\
(83 \%)\end{array}$ & 12 & 0 & 6 & 6 \\
\hline Medicine (MED) & $\begin{array}{c}54 \\
(48 \%)\end{array}$ & 36 & 18 & 37 & 17 \\
\hline Nursing (NUR) & $\begin{array}{c}42 \\
(95 \%)\end{array}$ & 35 & 7 & 25 & 17 \\
\hline Physiotherapy (PT) & $\begin{array}{c}27 \\
(74 \%)\end{array}$ & 16 & 11 & 19 & 8 \\
\hline Social Work (SW) & $\begin{array}{c}27 \\
(96 \%)\end{array}$ & 24 & 3 & 27 & 0 \\
\hline $\begin{array}{l}\text { Total } \\
\text { (\% Female) }\end{array}$ & $\begin{array}{c}162 \\
(75 \%)\end{array}$ & $\begin{array}{c}123 \\
(71 \%)\end{array}$ & $\begin{array}{c}39 \\
(85 \%)\end{array}$ & $\begin{array}{c}114 \\
(76 \%)\end{array}$ & $\begin{array}{c}48 \\
(71 \%)\end{array}$ \\
\hline
\end{tabular}


150

Student Beliefs about Poverty and Health

Proctor, Lake, Jewell, Racine, D'Eon, \& Reeder

Journal of Research in Interprofessional Practice and Education

Vol. 1.2

August, 2010

\section{Measures}

Students completed the Attitudes toward Poverty Scale (APS) and the Beliefs about the Relationship between Poverty and Health (BRPH) at the beginning of the project (Week 1) and then again at the end of the project (Week 5). Both measures were completed in large group sessions except for the first administration of the BRPH, which was done as part of the online modules. At Week 5 participants were also asked to complete six project-related evaluation items and to provide written comments to open-ended questions about the project (see Appendix B). Participants rated their agreement with the six project-related items using a 5-level Likert scale (A Strongly disagree, B Disagree, C Unsure, D Agree, E Strongly agree); responses were recorded as $\mathrm{A}=1, \mathrm{~B}=2, \mathrm{C}=3, \mathrm{D}=4$, and $\mathrm{E}=5$.

The APS was developed in the United States to measure attitudes toward poverty among undergraduate students [12]. In our study, items 7, 30, and 31 were reworded to suit the Canadian context of the present study, using the term "welfare" instead of "food stamps," and "taxpayers' money" instead of "federal budget" (see Appendix A). Participants rated their agreement with each of 37 statements using a 5-level Likert scale (A Strongly disagree, B Disagree, C Unsure, D Agree, E Strongly agree). Responses were recorded as $\mathrm{A}=1, \mathrm{~B}=2, \mathrm{C}=3, \mathrm{D}=4$, and $\mathrm{E}=5$, resulting in a possible range of scores from 37 to 185 . Ratings were inverted for data analysis so that higher ratings reflected more positive attitudes. In the present study, the APS had a Cronbach's alpha coefficient of 0.92 , consistent with previous reports of high internal consistency for this scale (Cronbach's alpha $=0.89$ to 0.93 ) [12].

The BRPH was originally developed to explore public perceptions of the relationship between poverty and health [13]. This measure consists of eight items related to four explanations of the relationship between poverty and health: causal (Item 1), drift (Item 2), behavioral (Items 3, 4, 5) and structural (Items 6, 7, 8) (see Table 4). Specifically, the causal explanation represents poverty as leading to poor health, while the drift explanation represents ill health as a precursor to poverty rather than a consequence of it. The behavioral explanations purport that people living in poverty are more likely to engage in unhealthy behaviors. Finally, the structural explanations indicate that poor health results from limited access to resources that facilitate health, as well as from living in conditions that do not promote health. Reutter and colleagues [14] reported that Canadian baccalaureate nursing students were more likely to endorse structural explanations than other explanations, and that support for structural explanations was associated with more positive attitudes toward poverty and with more exposure to poverty through course work. Participants rated their agreement with each statement using a 5-level Likert scale (A Strongly disagree, B Disagree, C Unsure, D Agree, E Strongly agree); responses were recorded as $\mathrm{A}=1, \mathrm{~B}=2, \mathrm{C}=3, \mathrm{D}=4$, and $\mathrm{E}=5$.

SPSS software (version 15.0) was used for all statistical calculations. Repeated measures ANOVAs were used to test for changes in participants' attitudes and beliefs over the course of the project, to compare students from different programs, to compare male and female students, to compare instructional methods (i.e., Poverty Awareness Workshop vs. Guest Interview), and to compare SWITCH vol- 
JRIPE

151

Student Beliefs about Poverty and Health

Proctor, Lake, Jewell, Racine, D'Eon, \& Reeder

Journal of Research in Interprofessional Practice and Education

Vol. 1.2

August, 2010

\section{Journal of Research in Interprofessional Practice and Education}

unteers and non-volunteers. Post-hoc comparisons were computed using Tamhane's T2, a conservative test that is considered more appropriate than Tukey's HSD when cell sizes are unequal and the assumption of homogeneity of variance is not met, as was the case for our sample. Content analysis was used to analyze data emerging from the open-ended questions. Specifically, the responses were analyzed for themes and patterns, and instances of a given theme were counted [15].

\section{Results}

A repeated measures ANOVA was performed for participants who completed the APS both at Week 1 and at Week 5, with time of test as the within-subjects variable and program as the between-subjects variable (see Table 3). There was a significant main effect for time of test, indicating a small but statistically significant increase toward more positive attitudes from Week 1 to Week $5(F[1,110]=7.97, p<.01)$. There was also a statistically signifiTable 3

Mean scores for Attitudes toward Poverty Scale (APS)

\begin{tabular}{|c|c|c|c|}
\hline Program & $N$ & $\begin{array}{c}\text { Week } 1 \\
\text { (SD) }\end{array}$ & $\begin{array}{c}\text { Week } 5 \\
\text { (SD) }\end{array}$ \\
\hline Kinesiology (KIN) & 11 & $\begin{array}{l}126.7 \\
(5.2)\end{array}$ & $\begin{array}{l}129.7 \\
(7.1)\end{array}$ \\
\hline Medicine (MED) & 30 & $\begin{array}{l}134.2 \\
(14.9)\end{array}$ & $\begin{array}{l}139.3 \\
(19.0)\end{array}$ \\
\hline Nursing (NUR) & 31 & $\begin{array}{l}129.1 \\
(13.2)\end{array}$ & $\begin{array}{l}132.4 \\
(13.7)\end{array}$ \\
\hline Physiotherapy (PT) & 21 & $\begin{array}{l}134.2 \\
(9.7)\end{array}$ & $\begin{array}{r}132.3 \\
(11.2)\end{array}$ \\
\hline Social Work (SW) & 22 & $\begin{array}{l}144.7 \\
(12.4)\end{array}$ & $\begin{array}{l}149.3 \\
(14.1)\end{array}$ \\
\hline Total & 115 & $\begin{array}{l}134.1 \\
(13.5)\end{array}$ & $\begin{array}{c}137.1^{*} \\
(15.8)\end{array}$ \\
\hline
\end{tabular}

Note: Possible scores range from 37 (least positive) to 185 (most positive). ${ }^{*} p<0.01$ cant main effect for program $(F[4,110]=6.84, p<.01)$. Post-hoc comparisons indicated that SW students had significantly more positive attitudes than students from KIN, NUR, and PT. The interaction of program and time of test was not significant.

Table 4 shows the mean rating for each item of the BRPH at Week 1 and Week 5. We also calculated the percentage of participants who agreed (ratings of 4 or 5 ) with each BRPH item at Week 1 . At the start of our project, a large majority $(88 \%)$ of our participants agreed that poverty leads to poor health, while only $36 \%$ agreed with the drift explanation. Few of our participants agreed with the three behavioral explanations $(6 \%, 13 \%$, and $12 \%$, respectively). Over half of our participants agreed with each of the three structural explanations $(61 \%, 78 \%$, and $56 \%$, respectively).

A repeated measures ANOVA was performed for each BRPH item, with time of test as the within-subjects variable, and program as the between-subjects variable. There was a significant main effect for time of test for three items. Participants agreed significantly less at Week 5 with two behavioral explanations (Item 3, $F[1$, $114]=5.07, p<.05$; Item $4, F[1,114]=11.00, p<.01)$ and one structural explanation $($ Item $8, F[1,112]=11.09, p<.01)$. 


\section{JRIPE}

152

Student Beliefs about Poverty and Health

Proctor, Lake, Jewell, Racine, D’Eon, \& Reeder
Table 4

\section{Mean ratings on Beliefs about the Relationship between Poverty and Health (BRPH)}

\begin{tabular}{|c|c|c|c|c|}
\hline \multirow{2}{*}{$\begin{array}{l}\text { Item } \\
\text { Number }\end{array}$} & \multirow{2}{*}{ Category } & \multirow{2}{*}{ Item } & \multicolumn{2}{|c|}{$\begin{array}{l}\text { Mean Rating } \\
(N=119)\end{array}$} \\
\hline & & & Week 1 & Week 5 \\
\hline 1 & Causal & Poverty leads to poor health. & 4.21 & 4.17 \\
\hline 2 & Drift & People become poor after they get sick and are unable to work. & 3.11 & 3.04 \\
\hline 3 & \multirow{3}{*}{ Behavioural } & $\begin{array}{l}\text { Poor people are unhealthy because they are not motivated to look after } \\
\text { their health. }\end{array}$ & 1.92 & $1.76^{*}$ \\
\hline 4 & & $\begin{array}{l}\text { Poor people are unhealthy because they do not know the effects of } \\
\text { harmful behaviours such as smoking. }\end{array}$ & 2.29 & $2.00^{* *}$ \\
\hline 5 & & Poor people are unhealthy because they lack the skills to manage money. & $2.09 a$ & $2.12 \mathrm{a}$ \\
\hline 6 & \multirow{3}{*}{ Structural } & $\begin{array}{l}\text { Poor people are unhealthy because society creates barriers that reduce } \\
\text { their opportunity for employment. }\end{array}$ & 3.66 & 3.66 \\
\hline 7 & & $\begin{array}{l}\text { Poor people are unhealthy because they live under more stressful } \\
\text { conditions. }\end{array}$ & 3.96 & 3.87 \\
\hline 8 & & Poor people are unhealthy because they get inadequate healthcare. & $3.62 b$ & $3.26 b^{* *}$ \\
\hline
\end{tabular}

Note: Mean of the following ratings: 1 Strongly disagree, 2 Disagree, 3 Unsure, 4 Agree, 5 Strongly agree. a $N=118$, b $N=117{ }^{*} p<0.05{ }^{* *} p<0.01$

The repeated measures ANOVA also revealed significant main effects for program for six BRPH items. Post-hoc analyses revealed that, compared with students from some other programs, SW students agreed significantly less with two behavioral explanations and significantly more with two structural explanations. Specifically, SW students agreed less than KIN students with Item $3(F[4,114]=3.80, p<.01)$, agreed less than NUR students with Item $4(F[4,114]=2.55, p<.05)$, agreed more than PT students with Item $6(F[4,114]=3.92, p<.01)$, and agreed more than PT and NUR students with Item $7(F[4,114]=3.25, p<.05)$. As well, PT students agreed less than MED and NUR students with Item $1(F[4,114]=4.72, p<.01$, and less than MED students with Item $2(F[4,114]=3.36, p<.05)$.

Repeated measures ANOVAs were also used to examine the effect of instructional method (Poverty Awareness Workshop vs. Guest Interview) on the APS and $\mathrm{BRPH}$, with time of test as a within-subjects variable and instructional method as a between-subjects variable. There were no significant findings for instructional method on the APS, but there was a significant interaction between instructional method and time of test for one item on the BRPH $(F[1,114]=4.23, p<.05)$. The Guest Interview group agreed less with Item 8 at Week $5(M=3.22, S D=0.93)$ than at Week $1(M=3.72, S D=1.05)$, while the Poverty Awareness Workshop group did not show this same degree of change over time (Week $5 M=3.34, S D=1.03$; Week 1 $M=3.40, S D=0.98)$. The fact that no SW students participated in the Poverty Awareness Workshop may have been a confounding factor; however, there was not a significant difference between SW students and other students in their agreement with this item. 
Student Beliefs about Poverty and Health

Proctor, Lake, Jewell, Racine, D'Eon, \& Reeder

Journal of Research in Interprofessional Practice and Education

Vol. 1.2

August, 2010

\section{Journal of Research in Interprofessional Practice and Education}

Finally, repeated measures ANOVAs were used to examine the differences between SWITCH volunteers and non-volunteers on the APS and the BRPH, with time of test as a within-subjects variable and volunteer status as a between-subjects variable. There were no significant findings for volunteer status on either measure. Similarly, there were no significant findings for comparisons of male and female students.

To summarize our participants' evaluations of the IPHP, we calculated the percentage of participants who agreed (ratings of 4 or 5) with each item evaluating the project. The majority of participants (55\%) agreed that they enjoyed participating in the IPHP, while only $36 \%$ agreed that the project achieved the intended objectives. Most participants agreed that Community Plunge (67\%) was interesting and worthwhile, while few felt the same way about the Pathways to Collaboration (online) modules (20\%). Participants in the Guest Interview were more likely to agree that it was interesting and worthwhile (62\%) than participants in the Poverty Awareness Workshop (8\%).

Of the 145 students who provided written comments, 35\% reported that they most liked the interprofessional context: meeting, working with, and learning about students from other health sciences. Another 32\% stated that they most liked the Community Plunge, including becoming familiar with a core neighbourhood, walking through it, and learning about services available there. A KIN student commented that it was "an eye-opening experience." The Guest Interview was the highlight for 21\%: they appreciated learning from the real-life experiences of people currently living in poverty. One PT student stated, "I gained a lot of insight into the life of a person of low SES." Finally, 12\% most liked participating in SWITCH. A MED student commented, "I think that [SWITCH] is where I learned the most about working with other healthcare professionals." For reference, $76 \%$ of the students participated in the Community Plunge, 70\% in the Guest Interview, and 24\% in SWITCH.

Challenges or difficulties identified by the students were more diverse. Some common themes were as follows: not enough time allocated for interdisciplinary teamwork, difficulty in scheduling or finding time to participate in the project, not understanding the goals of the project, not being able to empathize with the assigned character during the Poverty Awareness Workshop, or not having adequate interview skills or time to prepare for the Guest Interview. Students recommended that in the future more emphasis should be placed on the interdisciplinary aspect of this project, with more time for students from different health sciences to interact. Some students thought that SWITCH should become a mandatory component of the project because it provides a real-life interdisciplinary experience. In addition, a few students suggested that the Poverty Awareness Workshop should be either shortened or replaced with an opportunity to meet real people who are living in poverty, while others thought the Community Plunge (especially the community walk) should be lengthened.

\section{Discussion}

Our results indicate that even a brief program of interactive community-based learn- 
154

Student Beliefs about Poverty and Health

Proctor, Lake, Jewell, Racine, D'Eon, \& Reeder

Journal of Research in Interprofessional Practice and Education

Vol. 1.2

August, 2010 ing experiences can change health sciences students' attitudes toward individuals living in poverty. Although the change in APS score was small, we suggest that it is meaningful for two reasons. First, our participants started the project with strongly positive attitudes, with a mean (standard deviation in parentheses) of 134.1 (13.5), compared with 110.4 (14.7) for 113 American undergraduate students taking a course in business administration [12], 119.6 (21.9) for 98 American undergraduate students taking courses in sociology or social work [12], 125.5 (16.7) for 740 Canadian undergraduate nursing students [14], and 130.3 (19.9) for 180 Mississippi social workers [16]. The second reason for considering this change in attitude meaningful is that it was in the opposite direction than one would expect from simple regression to the mean. We recommend further research on the APS to improve this measure's psychometric properties, including exploration of its factor structure and identification of redundant or poor items.

Students also showed small but important changes in their beliefs about the relationship between poverty and health, though the pattern of results was somewhat unexpected. Instead of finding that students agreed more strongly with structural explanations at the end of the project, we found that they disagreed more strongly with two behavioral explanations of the relationship between poverty and health (relating to the motivation and knowledge of poor people), and also agreed less with the structural explanation of inadequate healthcare. One possible explanation of this finding is that students met people living in poverty who were well informed, motivated to look after their health, and accessed healthcare appropriately, thus challenging students' stereotypes about poor people. This explanation is supported by the fact that students who participated in the Guest Interview agreed less with the structural explanation of inadequate healthcare at the end of the project, while students who participated in the Poverty Awareness Workshop did not show this change. Further research is needed to discover whether these findings are robust and to evaluate whether these changes in beliefs are indeed positive ones for future healthcare professionals.

Students clearly valued the opportunity to work with and learn from students from other health sciences programs. In fact, they appeared frustrated that they had insufficient time to exploit this opportunity. Our objective for students to develop attitudes and skills necessary for successful interdisciplinary teamwork may have been too ambitious for this brief project, combined as it was with three other objectives. Perhaps this is why only $36 \%$ of the students agreed that the IPHP met the intended objectives. Nevertheless, our interprofessional learning environment did increase diversity: students from different programs (especially SW students) brought different attitudes and beliefs. Specifically, IPHP faculty noted that SW students as a group were more likely to have personal experience of living in poverty. There is evidence that students' socioeconomic status contributes to their attitudes and beliefs in this area [14]; however, further research is needed to explore how it affects attitude change.

Our participants preferred interactive experiences with real people to simulated experiences. The lack of enthusiasm at the end of the project for the Poverty 
155

Student Beliefs about Poverty and Health

Proctor, Lake, Jewell, Racine, D'Eon, \& Reeder

Journal of Research in Interprofessional Practice and Education

Vol. 1.2

August, 2010
Awareness Workshop surprised us, for our workshop facilitators had the impression that most students engaged fully in this workshop and found the experience to be powerful. The workshop did have a significant emotional component-the game is designed to provoke feelings of isolation, frustration, and hopelessness associated with living in poverty. Perhaps, by the end of the project, students remembered these negative feelings more than their insights. We wonder if there might be a positive rebound in the long term: another topic for future research.

We anticipated that participants who volunteered for SWITCH might differ from non-volunteers in their attitudes toward people living in poverty, but this was not the case. This finding does not rule out the possibility that SWITCH volunteers differed from non-volunteers in other kinds of beliefs and attitudes. In any event, our participants' evaluations made it clear that both SWITCH and the Community Plunge were positively received.

One potential limitation of our research is that there was significant attrition. Specifically, $84 \%$ of the students enrolled in the IPHP agreed to participate in the research, and the percentage of these participants who completed the APS and the BRHP both pre- and post-project was $71 \%$ and $73 \%$, respectively. Students who did not agree to participate in the research or who did not complete both measures may have had less positive attitudes than those who did. We did analyze the data for all enrolled students for the purpose of course evaluation and the outcomes were essentially unchanged, suggesting that any attrition effects were likely minimal.

Another limitation is that our results may not generalize to health sciences students from other geographical regions or settings. Specifically, the core values and attitudes of students from Saskatchewan, the birthplace of universal public medical insurance (Medicare) in Canada, may differ from those of other students. This speculation is supported by the fact that our participants agreed more with the drift explanation and all three structural explanations than 740 nursing students from across Canada [14]. Alternatively, our participants' higher ratings may have been an artifact of our using five-level Likert items for the BRPH rather than seven-level items used in Reutter's study; there is evidence that using rating scales with fewer levels inflates the ratings [17].

A final limitation of our study was that it was not possible to include a control group (i.e., a group of students who did not participate in the IPHP). As such, the findings are subject to several threats to internal validity [18]. For instance, we cannot know the extent to which changes in students' attitudes toward poverty and beliefs about poverty may have changed in the absence of participation in the IPHP and whether the observed results were due to factors such as maturation or history effects (e.g., content learned in concurrent classes could have influenced students' attitudes).

\section{Conclusion}

In summary, our study contributes to the literature by showing that modest changes in students' attitudes and beliefs about poverty and health can be achieved through a brief experiential learning program. We agree with other educators that to help 


\section{JRIPE}

156

Student Beliefs about Poverty and Health

Proctor, Lake, Jewell, Racine, D'Eon, \& Reeder
Journal of Research in Interprofessional Practice and Education

Vol. 1.2

August, 2010
Journal of Research in Interprofessional Practice and Education

students develop a public health perspective where they are less likely to blame the poor, it is essential to provide positive, interactive experiences with individuals living in poverty along with input from experts in the field [14, 19]. Like Wear and Kuczewski, we "hold on to the belief that education matters, that thoughtful, targeted experiences-both in classrooms and clinical settings-have the potential to deepen, enlarge, and even change the perspectives, attitudes, and career goals of trainees" [19, p. 644]. Furthermore, we believe that the development of such an "inequalities imagination" may be accelerated when it takes place in an interprofessional educational environment because of the increased diversity of the student body. Finally, we affirm the importance of program evaluation to monitor how educational experiences affect students' attitudes and beliefs.

\section{Acknowledgements}

The authors thank Melissa MacFadden, IPHP coordinator; Louise Buhler, IICUSP coordinator; as well as Bart Arnold, Bonnie Schoenfeld, and Judy White for their contributions to this project.

\section{Abbreviations}

APS: Attitudes toward Poverty Scale

BRPH: Beliefs about the Relationship between Poverty and Health

IICUSP: International Interdisciplinary Community-University Student Partnership

IPHP: Interdisciplinary Population Health Project

KIN: Kinesiology

MED: Medicine

NUR: Nursing

P-CITE: Patient-Centered Interprofessional Team Experiences

PT: Physical Therapy

SES: Socioeconomic status

SW: Social work

SWITCH: Student Wellness Initiative toward Community Health

\section{References}

1. Labonte, R., Polanyi, M., Muhajarine, N., McIntosh, T., \& Williams, A. (2005). Beyond the divides: Towards critical population health research. Critical Public Health, 15(1), 5-17.

2. Sistrom, M.G., \& Hale, P.J. (2006). Outbreak investigations: Community participation and role of community and public health nurses. Public Health Nursing, 23(3), 256-263.

3. Lemstra, M., Neudorf, C., \& Opondo, J. (2006). Health disparity by neighbourhood income. Canadian Journal of Public Health, 97(6), 435-439.

4. Lemstra, M., Neudorf, C., Opondo, J., de Bruin, P., Grauer, K., \& Wright, J. (2007). Epidemiological analysis of chlamydia trachomatis and neisseria gonorrhoeae in Saskatoon Health Region. Canadian Journal of Public Health, 98(2), 134-137.

5. Hart, A., Hall, V., \& Henwood, F. (2003). Helping health and social care professionals to develop an 'inequalities imagination': A model for use in education and practice. Journal of Advanced Nursing, 41(5), 480-489.

6. Campinha-Bacote, J. (1999). A model and instrument for addressing cultural competence in healthcare. Journal of Nursing Education, 38(5), 203-207. 
JRIPE

157

Student Beliefs about Poverty and Health

Proctor, Lake, Jewell, Racine, D'Eon, \& Reeder

7. Oneha, M.F., Yoshimoto, C.M., Bell, S., \& Enos, R.N. (2001). Educating health professionals in a community setting: What students value. Education for Health, 14(2), 256-266.

8. D’Eon, M. (2005). A blueprint for interprofessional learning. Journal of Interprofessional Care, 19(Suppl. 1), 49-59.

9. Green, A.R., Betancourt, J.R., \& Carrillo, J.E. (2002). Integrating social factors into cross-cultural medical education. Academic Medicine, 77(3), 193-197.

10. Cruce, T.M., Moore, J.V. III. (2007). First-year students' plans to volunteer: An examination of the predictors of community service participation. Journal of College Student Development, 48(6), 655-673.

11. Chapman, J.G., \& Morley, R. (1999). Collegiate service-learning: Motives underlying volunteerism and satisfaction with volunteer service. Journal of Prevention \& Intervention in the Community, 18(1-2), 19-33.

12. Atherton, C.R., Gemmel, R.J., Haagenstad, S., \& Holt, D.J. (1993). Measuring attitudes toward poverty: A new scale. Social Work Research \& Abstracts, 29(4), 28-30.

13. Reutter, L., Neufeld, A., \& Harrison, M.J. (1999). Public perceptions of the relationship between poverty and health. Canadian Journal of Public Health, 90(1), 13-18.

14. Reutter, L.I., Sword, W., Meagher-Stewart, D., \& Rideout, E. (2004). Nursing students' beliefs about poverty and health. Journal of Advanced Nursing, 48(3), 299-309.

15. Patton, M.Q. (2002). Qualitative research and evaluation methods (3rd ed). Thousand Oaks, CA: Sage.

16. Rehner, T., Ishee, J., Salloum, M., \& Velasues, D. (1997). Mississippi social workers' attitudes toward poverty and the poor. Journal of Social Work Education, 33(1), 131-42.

17. Dawes, J. (2008). Do data characteristics change according to the number of scale points used? An experiment using 5-point, 7-point and 10-point scales. International Journal of Market Research, 50(1), 61-77.

18. Shadish, W.R., Cook, T.D., \& Campbell, D.T. (2002). Experimental and quasi-experimental designs for generalized causal inference. Boston, MA: Houghton Mifflin Company.

19. Wear, D.K., \& Kuczewski, M.G. (2008). Perspective: Medical students' perceptions of the poor: What impact can medical education have? Academic Medicine, 83(7), 639-645.

\section{Appendix A: Attitudes toward Poverty Scale (adapted from [12])}

${ }^{*}$ Indicates that the item was reverse scored.

1. A person receiving welfare should not have a nicer car than I do.

2. Poor people will remain poor regardless of what's done for them.

3. Welfare makes people lazy.

4. Any person can get ahead in this country.

5. Poor people are satisfied receiving welfare.

6. ${ }^{\star}$ Welfare recipients should be able to spend their money as they choose.

7. An able-bodied person using welfare to buy groceries is ripping off the system.

8. Poor people are dishonest.

9. If poor people worked harder, they could escape poverty.

10. Most poor people are members of a minority group.

11. ${ }^{\star}$ People are poor due to circumstances beyond their control.

12. ${ }^{\star}$ Society has the responsibility to help poor people.

13. People on welfare should be made to work for their benefits.

Journal of Research in Interprofessional

Practice and

Education

14. Unemployed poor people could find jobs if they tried harder.

15. Poor people are different from the rest of society.

16. Being poor is a choice.

17. Most poor people are satisfied with their standard of living.

Vol. 1.2

August, 2010 


\section{JRIPE}

158

Student Beliefs about Poverty and Health

Proctor, Lake, Jewell, Racine, D'Eon, \& Reeder

Journal of Research in Interprofessional Practice and Education

Vol. 1.2

August, 2010

\section{Journal of Research in Interprofessional Practice and Education}

19. Mothers on welfare have babies to get more money.

20. Children raised on welfare will never amount to anything.

21. Poor people act differently.

22. ${ }^{\star}$ Poor people are discriminated against.

23. Most poor people are dirty.

24. *People who are poor should not be blamed for their misfortune.

25 . ${ }^{*}$ If I were poor, I would accept welfare benefits.

26. Out-of-work people ought to have to take the first job that is offered.

27. The government spends too much money on anti-poverty programs.

28. Some poor people live better than I do, considering all their benefits.

29. There is a lot of fraud among welfare recipients.

30. Benefits for poor people consume a major part of taxpayers' money.

31. ${ }^{\star}$ Poor people use their welfare money to buy groceries wisely.

32. Poor people generally have lower intelligence than non-poor people.

33. Poor people should be more closely supervised.

34. I believe poor people have a different set of values than do other people.

35. I believe poor people create their own difficulties.

36. ${ }^{\star}$ I believe I could trust a poor person in my employ.

37. ${ }^{\star}$ I would support a program that resulted in higher taxes to support social programs for poor people.

\section{Appendix B: Post-Evaluation Items Project-related evaluation items}

1. I think this project achieved the intended objectives.

2. Overall, I enjoyed participating in the Interdisciplinary Population Health Project.

3. The "Pathways to Collaboration" modules (online) were interesting and worthwhile.

4. The "Community Plunge" session was interesting and worthwhile.

5. The "Guest Interview" session was interesting and worthwhile.

6. The "Poverty Awareness Workshop" was interesting and worthwhile. Open-ended evaluation items

1. The things I liked best about the whole project were...

2. The things I found most difficult or challenging about this project were...

3. The changes I would suggest to make this project better for next year are...

4. Additional comments... 